\title{
Superficial vs deep pancreatic parenchymal invasion in the extrahepatic bile duct carcinomas: a significant prognostic factor
}

\author{
Seung-Mo Hong ${ }^{1}$, Mi-Jung Kim ${ }^{1}$, HyungJun $\mathrm{Cho}^{2}$, David Y Pi ${ }^{1}$, Daniel Jo ${ }^{1}$, Eunsil Yu ${ }^{1}$ \\ and Jae Y Ro ${ }^{1, *}$ \\ ${ }^{1}$ Department of Pathology, Asan Medical Center, University of Ulsan, Seoul, Korea and ${ }^{2}$ Division of \\ Biostatistics and Epidemiology, University of Virginia Health System, Charlottesville, VA, USA
}

\begin{abstract}
Pancreatic invasion of the extrahepatic bile duct (EBD) carcinomas is known to have a poor outcome. We hypothesized that EBD carcinoma showing shallow invasion to the pancreas may have a better outcome than the usual deep pancreatic invasion. We divided 87 cases of the distal EBD carcinomas into superficial and deep pancreatic invasion groups according to degrees of the pancreatic invasion. The superficial pancreatic invasion group included cases with tumor abutting the pancreatic lobule or pancreatic parenchymal invasion equal to or less than $1 \mathrm{~mm}$ from the uppermost portion of the pancreatic lobule or tumors invading into the fibroadipose tissue between pancreatic lobules without parenchymal invasion. The deep invasion group consisted of tumors with more than $1 \mathrm{~mm}$ pancreatic parenchymal invasion. The cases with superficial pancreatic invasion showed significantly better survival rate than those with deep pancreatic invasion $(P<0.001)$. Therefore, we recommend that a specific remark on the pathology report about the presence or absence of parenchymal invasion and the depth of invasion of the pancreas is required for managing patients and determining the prognosis. We also recommend that the current pT3 stage of distal EBD carcinomas be subdivided into superficial (pT3a) and deep pancreatic invasion (pT3b).

Modern Pathology (2005) 18, 969-975. doi:10.1038/modpathol.3800380; Published online 15 April 2005
\end{abstract}

Keywords: extrahepatic bile duct carcinoma; pancreas; invasion; prognosis

Extrahepatic bile duct (EBD) carcinoma is an uncommon neoplasm with a dismal prognosis., The EBD carcinomas originating from the lower to middle portions of the bile duct (distal EBD carcinoma) are composed of $20-30 \%$ of the entire EBD carcinomas. ${ }^{3-9}$ The pancreatic invasion of the EBD carcinomas has been known to be a bad prognostic sign. ${ }^{10,11}$ However, we experienced that several patients with the EBD carcinoma with superficial pancreatic invasion had a more favorable survival outcome than we expected.

The pancreas has several histologic characteristics. One is that the pancreas does not have a discrete capsule and the other is that the pancreatic parenchyma is divided into lobules with intervening fibroadipose tissue. ${ }^{12-14}$ As a result of these

Correspondence: Professor JY Ro, Department of Pathology, Asan Medical Center, University of Ulsan College of Medicine, 388-1 Pungnap-dong, Songpa-ku, Seoul 138-736, Korea.

E-mail: jaero@amc.seoul.kr

${ }^{*}$ Currently at Methodist Hospital, 6565 Fannin Street, Houston, TX 77030, USA. E-mail: jaero@tmh.tmc.edu

Received 27 September 2004; revised 6 December 2004; accepted 30 December 2004; published online 15 April 2005 histologic characteristics, there is no well-defined boundary between the bile duct wall and the pancreas, and this anatomic feature makes pathologists have a difficulty in determining the depth of invasion when tumor cells invaded into fibroadipose tissue between pancreatic lobules without definite pancreatic parenchymal invasion in cases of the distal EBD carcinomas.

Based on our anecdotal experience, we hypothesized that the EBD carcinomas with a shallow superficial invasion to the pancreas or an invasion only to the fibroadipose tissue between pancreatic lobules without definite pancreatic parenchymal invasion may have a better outcome than the usual deep pancreatic parenchymal invasion. To test this hypothesis, we studied 87 cases of the distal EBD carcinomas after we divided them into superficial and deep pancreatic invasion groups.

\section{Materials and methods}

We reviewed 222 cases of surgically resected EBD carcinoma specimens from the file of the Department of Pathology at Asan Medical Center, 
University of Ulsan College of Medicine, Seoul, Korea from 1991 to 2000 . Only carcinomas with the epicenter in the EBD were included in this study. Either carcinomas with the epicenter in the ampulla of Vater or pancreas, or carcinomas with obvious precancerous epithelial changes in the ampulla of Vater or pancreas were excluded. Of these 87 cases were the distal EBD carcinomas containing both tumor and pancreatic sections. We classified the distal EBD carcinomas according to the degree of the pancreatic invasion. Tumors invading into the fibroadipose tissue between pancreatic lobules without pancreatic parenchymal invasion were classified as class 1 (Figure 1). Class 2 was the cases showing tumor cells abutting the pancreatic parenchyma or pancreatic parenchymal invasion equal to or less than $1 \mathrm{~mm}$ from the uppermost portion of the pancreatic lobule (Figure 2). Tumors

a
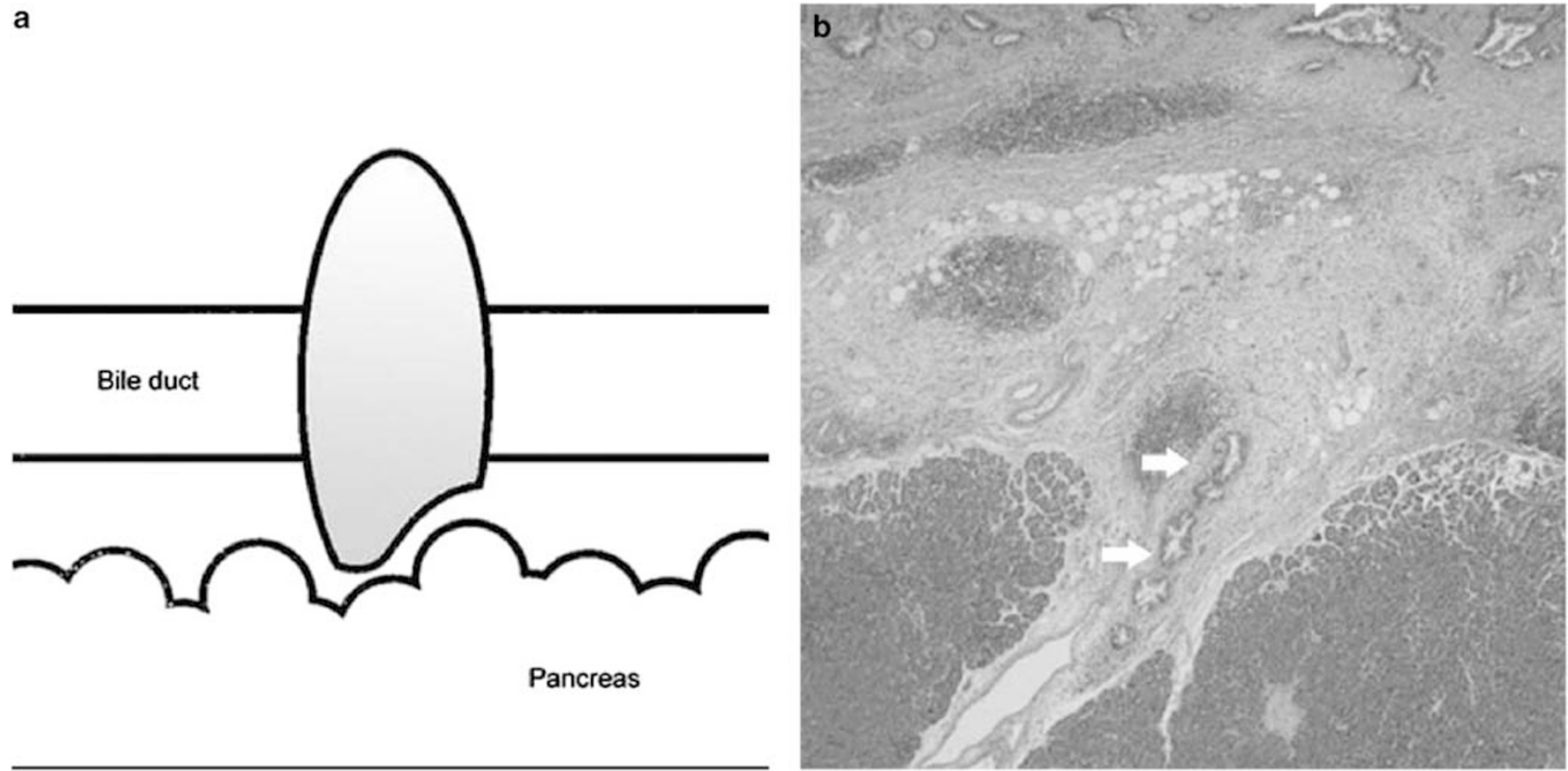

Figure 1 Class 1: tumor invading into the fibroadipose tissue between pancreatic lobules without pancreatic parenchymal invasion. (a) Schematic drawing and (b) microscopic picture with arrows indicating tumor glands in fibroadiopse tissue $(\times 40)$.

a

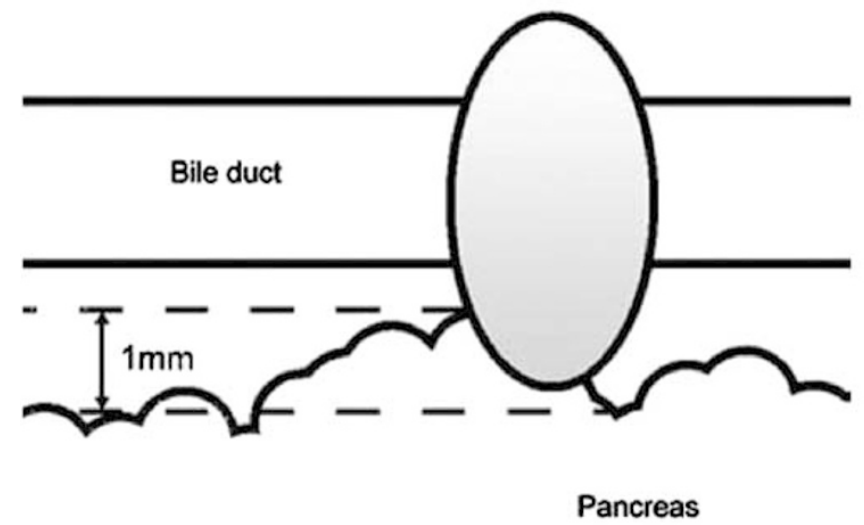
Figure 2 Class 2: tumor with tumor cells abutting the pancreatic parenchyma or tumor with pancreatic parenchymal invasion equal to or
less than $1 \mathrm{~mm}$. (a) Schematic drawing and (b) microscopic picture with arrows indicating tumor glands in the superficial portion of pancreatic parenchyma $(\times 40)$.

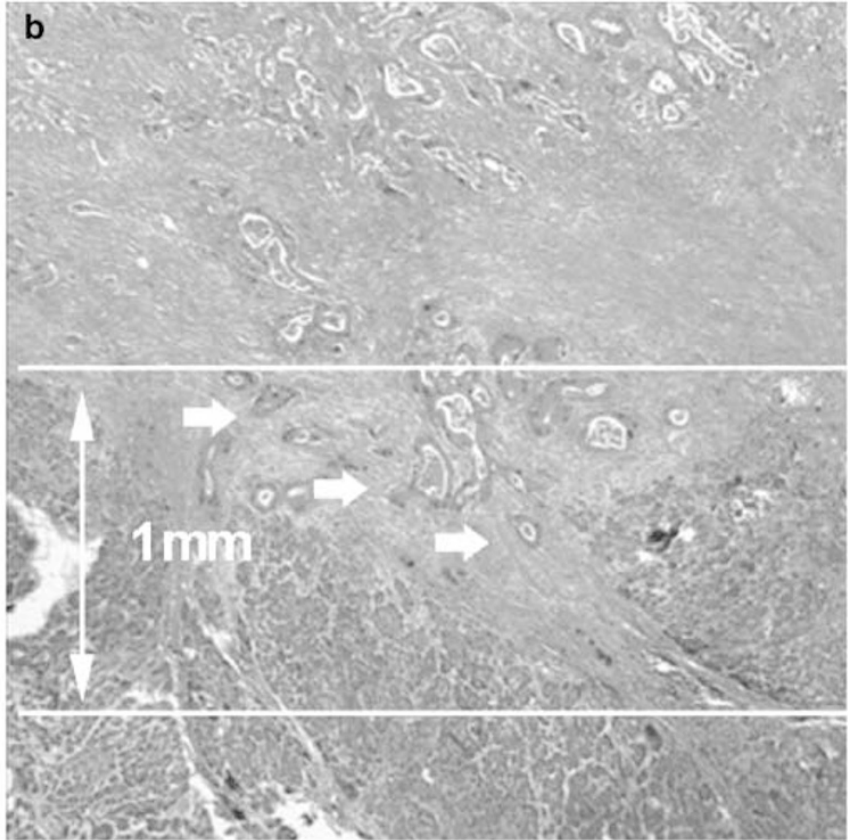



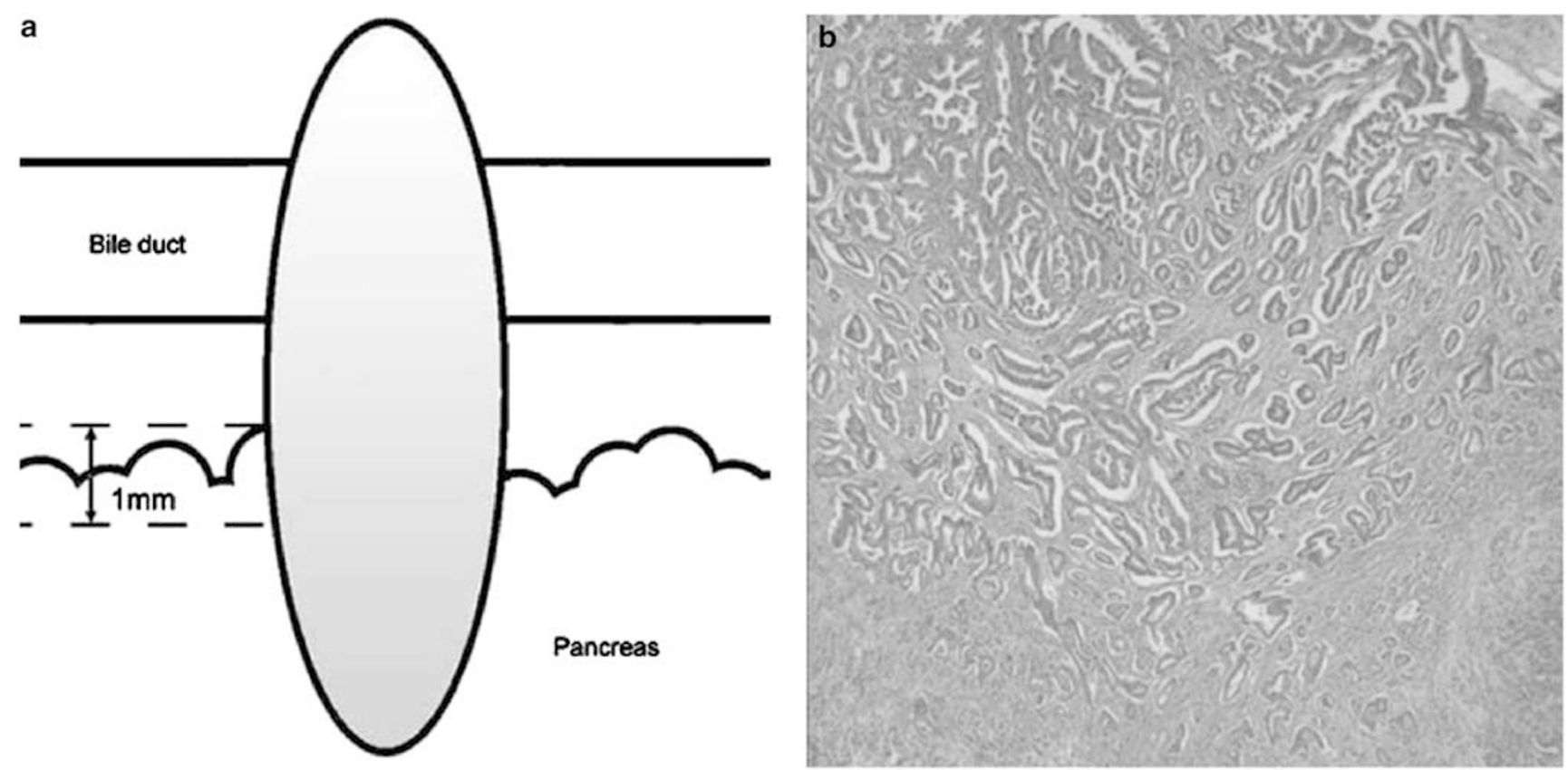

Figure 3 Class 3: tumor with pancreatic parenchymal invasion more than $1 \mathrm{~mm}$. (a) Schematic drawing and (b) microscopic picture $(\times 40)$.

invading more than $1 \mathrm{~mm}$ of pancreatic parenchyma were classified as class 3 (Figure 3). And then we defined classes 1 and 2 as the superficial pancreatic invasion group (group 1) and class 3 as the deep pancreatic invasion group (group 2). We made three wide-interval deeper sections in all cases in group 1 (classes 1 and 2) to avoid underestimation of the depth of invasion. To evaluate whether the effect of the depth of the pancreatic invasion is confounded with that of the lymph node metastasis, we performed correlation analysis between the depth of the pancreatic invasion and the lymph node metastasis. In addition, we investigated the effect of the depth of invasion for each of presence and absence of lymph node metastasis.

We classified histologic types according to the 6th American Joint Committee on Cancer (AJCC) cancer staging manual. ${ }^{8}$ We evaluated patients' survival according to other clinicopathologic factors including sex, age, size of the tumor, growth pattern, histologic type, metastasis to lymph nodes, marginal status, duodenal, perineural, and vascular invasion.

Statistical analyses were performed using SPSS 11.0 software (SPSS Inc., Chicago, IL, USA). Survival rate was calculated by the Kaplan-Meier method. Using the log rank test, we analyzed the survival rate of patients in classes 1,2 , and 3 . We also compared the survival rate between groups 1 and 2 to determine any significant difference in survival. Using the log rank test and Cox proportional hazards model, we investigated other prognostic factors, such as sex, age, size of the tumor, growth pattern, lymph node metastasis, resection marginal status, duodenal, perineural, and vascular invasion. $P<0.05$ was considered as statistically significant.

\section{Results}

\section{Clinicopathologic Characteristics of Cases}

Ages of the patients ranged from 30 to 78 years (mean: 60 years). In all, 63 cases were men and 24 were women. The tumors showed infiltrative growth pattern in 74 cases, papillary in nine, and nodular in four cases. The tumor size in 22 cases was less than $2 \mathrm{~cm}$, between 2 and $4 \mathrm{~cm}$ were 56 cases, and more than $4 \mathrm{~cm}$ were nine cases. Mean size of the tumor was $2.57 \mathrm{~cm}$. Nine cases showed duodenal invasion and none had the hepatic invasion. In all, 53 and 27 cases showed perineural and vascular invasion, respectively. In 11 cases tumor cells involved the resection margins. A total of 33 cases metastasized to lymph nodes. Histologic subtypes showed 72 cases of adenocarcinoma, NOS, six cases of papillary carcinomas, three cases of intestinal-type adenocarcinomas, two cases of adenosquamous carcinomas, and two cases of mucinous carcinomas. There was one case each of clear cell carcinoma and signet ring cell carcinoma. In all, 38 cases were performed standard pancreaticoduodenectomy (Whipple's operation) and 49 pylorus preserving pancreaticoduodenectomy.

Initially, there were five cases in class 1, 21 cases in class 2, and 61 cases in class 3. After deeper sectioning, two cases of class 1 were reclassified as class 2 and the final number was three cases in class 1 , 23 cases in class 2 , and 61 cases in class 3 . A total of 26 cases were group 1 (superficial pancreatic invasion), and 61 cases group 2 (deep pancreatic invasion). 


\section{Patients' Survival Rate among Each Class}

The survival rate of 1,3 , and 5 year and the median survival of each class are summarized in Figure 4. Although, the survival rate of 1,3 , and 5 year of the class 1 was $100,66.7$, and $66.7 \%$, there were only three cases for class 1 . It can be misleading to interpret the results with such a small number of cases. One-year survival rate of classes 2 and 3 was 87.0 and $63.4 \%$, three-year survival rate 60.3 and $21.8 \%$, and five-year survival rate 47.2 and $3.8 \%$, respectively. The median survival time of class 1 could not be obtained because two of three cases were censored. The median survival time of classes 2 and 3 were 65 and 19 months, respectively. Patients of class 2 showed significantly better survival than those of class $3(P<0.001)$.

\section{Patients' Survival Rate between Groups 1 and 2}

Classes 1 and 2 put together as group 1 and this group compared with group 2 (class 3). One-year survival rate of groups 1 and 2 was 88.5 and $63.4 \%$, 3-year survival rate 60.2 and $21.8 \%$ and 5-year survival rate 48.6 and $3.8 \%$, respectively. The median survival time of groups 1 and 2 was 65 and 19 months, respectively, and there was a significant survival difference between two groups $(P<0.001)$ (Figure 5, Table 1).

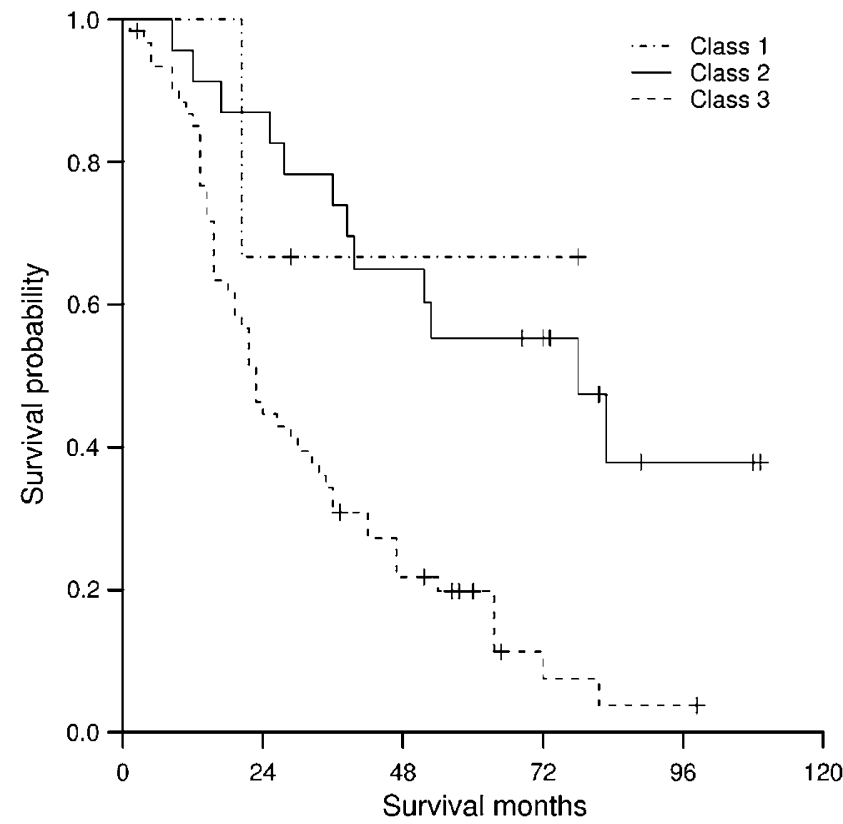

Figure 4 Kaplan-Meier survival analysis of each class. The median survival time of class 1 is not obtained because two of three patients are censored. The median survival time of classes 2 and 3 is 65 and 19 months, respectively. Patients of class 2 showed significantly better survival than that of class 3 $(P<0.001)$.
Table 1 Univariate analysis of other clinicopathologic factors for the prognosis

\begin{tabular}{|c|c|c|c|c|}
\hline Factor & Characteristics & Number & $\begin{array}{l}\text { Median } \\
\text { survival } \\
\text { (months) }\end{array}$ & $\mathrm{P}$-value \\
\hline \multirow{2}{*}{$\begin{array}{l}\text { Degree of } \\
\text { pancreatic } \\
\text { invasion }\end{array}$} & Group 1 & 26 & 65 & $<0.001^{*}$ \\
\hline & Group 2 & 61 & 19 & \\
\hline \multirow[t]{2}{*}{ Sex } & Male & 63 & 30 & 0.430 \\
\hline & Female & 24 & 21 & \\
\hline \multirow[t]{2}{*}{ Age } & $\leq 60$ years & 41 & 30 & 0.444 \\
\hline & $>60$ years & 46 & 25 & \\
\hline \multirow[t]{3}{*}{ Size } & $<2 \mathrm{~cm}$ & 22 & 33 & 0.144 \\
\hline & $2-4 \mathrm{~cm}$ & 56 & 20 & \\
\hline & $>4 \mathrm{~cm}$ & 9 & 39 & \\
\hline \multirow[t]{3}{*}{ Growth type } & Papillary & 9 & 32 & 0.807 \\
\hline & Nodular & 4 & 17 & \\
\hline & Infiltrative & 74 & 27 & \\
\hline \multirow{2}{*}{$\begin{array}{l}\text { Lymph node } \\
\text { metastasis }\end{array}$} & Present & 34 & 18 & 0.002 * \\
\hline & Absent & 53 & 39 & \\
\hline \multirow{2}{*}{$\begin{array}{l}\text { Duodenal } \\
\text { invasion }\end{array}$} & Present & 9 & 13 & $0.017^{*}$ \\
\hline & Absent & 78 & 30 & \\
\hline \multirow{2}{*}{$\begin{array}{l}\text { Resection } \\
\text { marginal status }\end{array}$} & Positive & 11 & 18 & 0.067 \\
\hline & Negative & 76 & 29 & \\
\hline \multirow{2}{*}{$\begin{array}{l}\text { Perineural } \\
\text { invasion }\end{array}$} & Present & 53 & 25 & 0.988 \\
\hline & Absent & 34 & 27 & \\
\hline \multirow{2}{*}{$\begin{array}{l}\text { Vascular } \\
\text { invasion }\end{array}$} & Present & 27 & 27 & $0.017^{*}$ \\
\hline & Absent & 60 & 35 & \\
\hline
\end{tabular}

*Significant at the significance level $<0.05$.

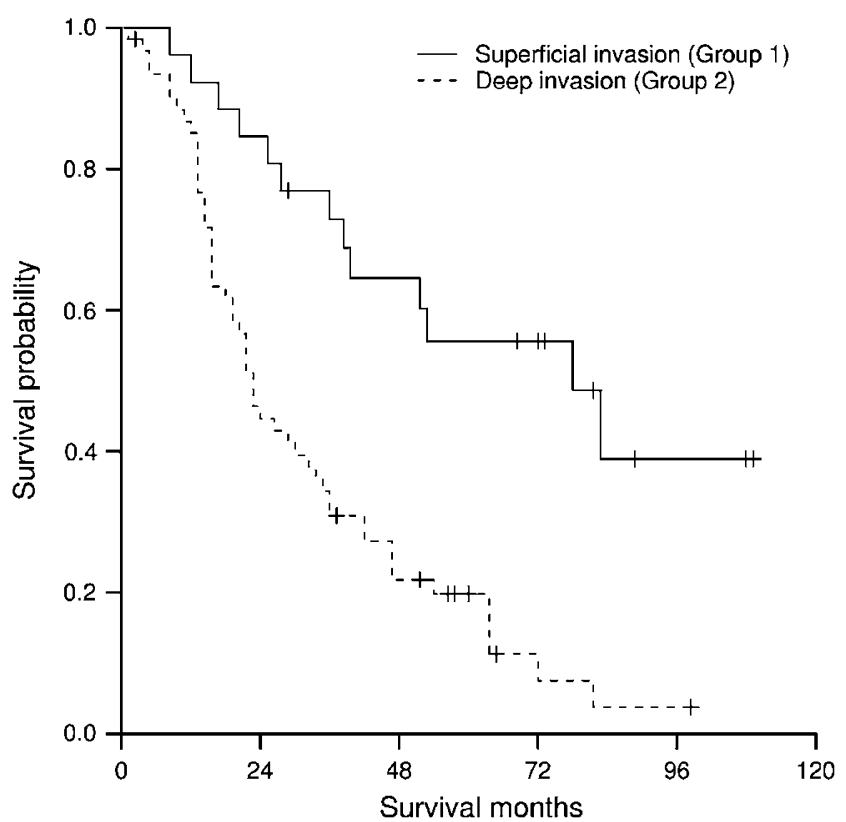

Figure 5 Kaplan-Meier survival analysis of the superficial (group 1) vs deep pancreatic (group 2) invasion. The median survival time of the superficial and the deep pancreatic invasion is 65 and 19 months, respectively. This difference is statistically significant $(P<0.001)$. 
Patients' Survival Rate between Groups 1 and 2 according to Status of Lymph Node Metastasis

Six of 26 cases in group 1 showed metastasis to lymph node, while 28 of 61 cases in group 2 demonstrated presence of lymph node metastasis. The $\chi^{2}$ test showed that the dependency between the depth of invasion and the status of lymph node metastasis was not so strong $(P=0.07)$. For the patients without lymph node metastasis, the median survival times of groups 1 and 2 were 69 and 29 months, respectively (Figure 6). The difference between two groups was statistically significant $(P<0.001)$. On the other hand, when lymph node metastasis was present, the median survival times of groups 1 and 2 were 28 and 18 months, respectively, and this difference was not statistically significant, although there was a trend for the better survival in group 1 (Figure 7 ). The number $(n=6)$ of cases in group 1 was too small to make a conclusion.

\section{Univariate Analyses of Other Clinicopathologic Variables}

Median survival times according to histologic type was as follows: 29 months in adenocarcinoma, NOS, 29.5 months in papillary carcinomas, 30 months in intestinal-type adenocarcinomas, 16.5 months in adenosquamous carcinomas, 43 months in mucinous carcinomas, 11 months clear cell carcinoma, and 3 months in signet ring cell carcinoma.

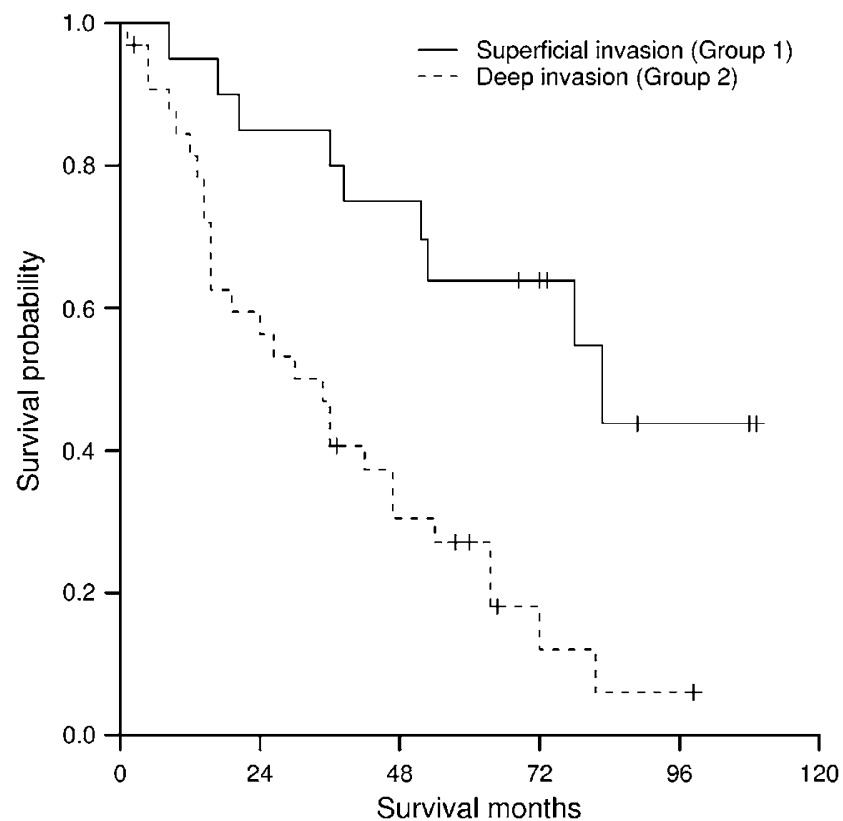

Figure 6 Kaplan-Meier survival analysis of the superficial (group 1) vs deep pancreatic (group 2) invasion with no lymph node metastasis. The median survival time of the superficial and the deep pancreatic invasion is 69 and 29 months, respectively. This difference is statistically significant $(P<0.001)$.
The univariate analyses using the log rank test showed that the lymph node metastasis $(P<0.005)$, the duodenal invasion $(P<0.05)$, and the vascular invasion $(P<0.05)$ were significantly associated with the overall survival (Table 1). There was no survival difference according to sex, age, size of tumor, growth type, resection marginal status, and perineural invasion.

\section{Multivariate Analysis for Prognosis}

The prognostic significance according to the degree of the pancreatic invasion along with other prognostically significant clinicopathologic variables was further analyzed by the Cox proportional hazards model. The multivariate analysis revealed that the degree of the pancreatic invasion was the most significant prognostic factor among other variables (Table 2).

Table 2 Multivariate analysis for the prognosis

\begin{tabular}{lccc}
\hline Variable & P-value & $\begin{array}{c}\text { Relative } \\
\text { risk }\end{array}$ & 95\% CI \\
\hline $\begin{array}{l}\text { Superficial vs deep pancreatic } \\
\text { invasion }\end{array}$ & $0.001^{*}$ & 2.932 & $1.541-5.587$ \\
$\begin{array}{l}\text { Lymph node metastasis } \\
\text { Duodenal invasion }\end{array}$ & 0.308 & 1.362 & $0.752-2.469$ \\
Vascular invasion & 0.161 & 1.764 & $0.798-3.906$ \\
& 0.080 & 1.616 & $0.944-2.770$ \\
\hline
\end{tabular}

CI, Confidence interval

*Significant at the significance level $<0.05$.

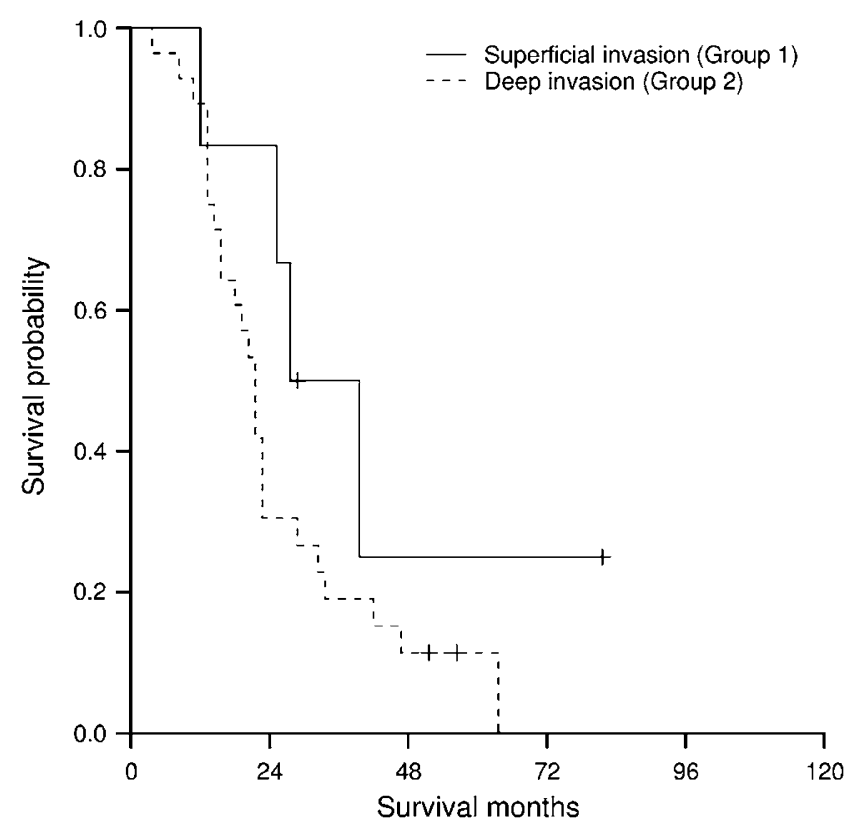

Figure 7 Kaplan-Meier survival analysis of the superficial (group 1) vs deep pancreatic (group 2) invasion with lymph node metastasis. The median survival time of the superficial and the deep pancreatic invasion is 28 and 18 months, respectively, and this difference is not statistically significant. 


\section{Discussion}

The EBD carcinomas are uncommon neoplasms, and the EBD carcinomas involving the lower to middle portion of the EBD (distal EBD carcinoma) account for $20-30 \%$ of the entire EBD carcinomas. ${ }^{3-9}$ The only effective treatment for the distal EBD carcinomas is a complete surgical resection. ${ }^{3,6,7}$ After complete resection of the distal EBD carcinomas, 5 -year survival rate was reported to be $15-45 \%$, while the median survival time of the patients having the palliative bypass surgery or biliary stent was reported to be less than 1 year., ${ }^{3,6,7,15-18}$ The patients with the EBD carcinomas are known to have a poor survival when pancreatic invasion is present. $^{10,11}$

In the present study, we classified the distal EBD carcinomas according to the degree of the pancreatic invasion and compared the survival rate of each class. Cases with equal to or less than $1 \mathrm{~mm}$ of the pancreatic invasion (class 2) showed better survival rate than cases with more than $1 \mathrm{~mm}$ of the pancreatic invasion (class 3) and this difference was statistically significant. Cases with tumors invading into the fibroadipose tissue between pancreatic lobules without definite pancreatic parenchymal invasion (class 1) looked alike better survival than class 2 cases. However, there was no statistically significant difference between classes 1 and 3 , because there were only three cases in classes 1 and 2 of them were censored. Therefore, for more concrete conclusion, further studies with more cases in class 1 are needed.

Microinvasion or superficial invasion in other malignant neoplasms, such as malignant melanoma and vulvar carcinoma, ${ }^{8}$ is defined as tumor invasion equal to or less than $1 \mathrm{~mm}$ from the surface. We applied the same definition to the EBD carcinomas and defined the superficial invasion as an invasion equal to or less than $1 \mathrm{~mm}$ from the uppermost portion of the pancreatic lobule (class 2). In this group, we also included tumors invading fibroadipose tissue between pancreatic lobules with no pancreatic parenchymal invasion (class 1). And then we classified the distal EBD carcinomas into the superficial (group 1) and deep pancreatic invasions (group 2).

Metastasis to lymph nodes has known to be the most important prognostic factor of the EBD carcinoma. ${ }^{6,16,19-21}$ The dependency between the depth of invasion and the status of lymph node metastasis was not statistically significant $(P=0.07)$. When lymph node metastasis was absent, group 2 demonstrated significantly worse survival than group 1 $(P<0.001)$, while when lymph node metastasis was present, the difference was not statistically significant $(P=0.17)$. However, the case number (six cases) of group 1 with lymph node metastasis was too small to make a conclusion. For more concrete conclusion based on lymph node status and depth of pancreatic invasion, further studies with larger number of cases and multivariate analysis are needed.

In the present study, tumor size was not associated with patients' survival. This result was the same as those of the previously reported. ${ }^{10,22}$ Tumor size is one of the important prognostic factors in tumors arising from solid parenchymal organs, while depth of invasion is one of the important prognostic factors in tumors of hollow viscus, such as intestine and urinary bladder. ${ }^{8}$ Our results demonstrated that the depth of invasion appear to be more important prognostic factor than tumor size when distal EBD carcinomas involved the pancreas.

In this study, we demonstrated that group 1 showed more favorable prognosis than group 2 . To the best of our knowledge, the prognostic significance of the EBD carcinomas according to the degree of pancreatic parenchymal invasion has not been analyzed. Our study demonstrated that cases with the superficial pancreatic parenchymal invasion appeared to have significantly better survival than those with the deep pancreatic invasion. Our results of the univariate and multivariate analyses revealed that the degree of the pancreatic invasion was the most important prognostic predictor in patients with distal EBD carcinomas. Therefore, when distal EBD carcinomas are present, we would like to propose that the current pT3 stage of the EBD carcinoma is subdivided into superficial (pT3a) and deep pancreatic invasion (pT3b).

The pancreas is a parenchymal organ with complex lobular structures and does not have a capsule. ${ }^{12-14}$ These anatomical characteristics create an ambiguous interphase between the bile duct wall and the pancreas. In addition, although the pancreas does not have an evenly flat layer of the parenchymal lobules, the AJCC staging system for the EBD carcinoma applied the similar criteria to the staging system of the other gastrointestinal organs. ${ }^{8}$ Specific explanations of the histologic characteristics of the pancreas would be needed in the future edition of the staging manual of the AJCC. We attempted to prove that the distal EBD carcinomas invading the fibroadipose tissue between pancreatic lobules without true parenchymal invasion affect the prognosis favorably than deep pancreatic invasion. However, we did not make a firm conclusion due to small number of cases of the tumor cells invading the fibroadipose tissue between pancreatic lobules without true parenchymal invasion in the present study. Therefore, additional studies for the prognosis of the distal EBD carcinoma cases with invasion into the fibroadipose tissue between pancreatic lobules without definite pancreatic parenchymal invasion are required.

In this study, the initial case number of class 1 was 5 . Two of the five class 1 cases were changed into class 2 after deeper sections were examined. Two cases revealed focal pancreatic parenchymal invasion less than $1 \mathrm{~mm}$. The deeper sectioning on two of class 2 cases which originally revealed tumor 
cells abutting to the pancreas (class 2) revealed focal pancreatic parenchymal invasion equal to less than $1 \mathrm{~mm}$ (also class 2). These results indicate that the deeper sectioning is required for determining the true depth of invasion. When pathologists feel it difficult to evaluate the depth of invasion on the initial sections particularly in cases with classes 1 and 2, deeper sections may be needed for the proper evaluation of the depth of pancreatic invasion.

In summary, this study indicated that when the EBD carcinomas invade less than or equal to $1 \mathrm{~mm}$ of the pancreas or invade only the fibroadipose tissue between pancreatic lobules without pancreatic parenchymal invasion, the prognosis is much better than that of tumors with deep pancreatic invasion with greater than $1 \mathrm{~mm}$ of invasion. Therefore, a specific remark on the presence or absence of pancreatic parenchymal invasion as well as the depth of invasion (less than or equal to $1 \mathrm{~mm} \mathrm{vs}$ more than $1 \mathrm{~mm}$ ) of the pancreas is required in the pathology report for the determining of the outcome in cases with distal EBD carcinomas. We also recommended that the current pT3 stage of the EBD carcinomas be divided into superficial (pT3a) and deep pancreatic invasion (pT3b), when distal EBD carcinoma is present.

\section{Acknowledgements}

This work was presented, in part, at the 93rd Annual Meeting of the United States and Canadian Academy of Pathology, Vancouver, BC, Canada, March 2004. We especially thank Mr Hyung-Min Lee for his technical support in graphics.

\section{References}

1 Albores-Saavedra J, Henson DE, Klimstra D. Tumors of the Gallbladder, Extrahepatic Bile Ducts, and Ampulla of Vater, 3rd edn, Fascicle 27. Armed Forces Institute of Pathology: Washington, DC, 2000.

2 Henson DE, Albores-Saavedra J, Corle D. Carcinoma of the extrahepatic bile ducts. Histologic types, stage of disease, grade, and survival rates. Cancer 1992; 70: 1498-1501.

3 Jarnagin WR. Cholangiocarcinoma of the extrahepatic bile ducts. Semin Surg Oncol 2000;19:156-176.

4 Launois B, Reding R, Lebeau G, et al. Surgery for hilar cholangiocarcinoma: French experience in a collective survey of 552 extrahepatic bile duct cancers. J Hepatobiliary Pancreat Surg 2000;7:128-134.

5 Tompkins RK, Saunders K, Roslyn JJ, et al. Changing patterns in diagnosis and management of bile duct cancer. Ann Surg 1990;211:614-620.
6 Fong Y, Blumgart LH, Lin E, et al. Outcome of treatment for distal bile duct cancer. Br J Surg 1996; 83:1712-1715.

7 Nakeeb A, Pitt HA, Sohn TA, et al. Cholangiocarcinoma. A spectrum of intrahepatic, perihilar, and distal tumors. Ann Surg 1996;224:463-473.

8 American Joint Committee on Cancer. AJCC Cancer Staging Manual, 6th edn. Springer-Verlag: New York, 2002.

9 Chung C, Bautista N, O’Connell TX. Prognosis and treatment of bile duct carcinoma. Am Surg 1998;64: 921-925.

10 He P, Shi JS, Chen WK, et al. Multivariate statistical analysis of clinicopathologic factors influencing survival of patients with bile duct carcinoma. World J Gastroenterol 2002;8:943-946.

11 Bhuiya MMR, Nimura Y, Kamiya J, et al. Clinicopathologic factors influencing survival of patients with bile duct carcinoma: multivariate statistical analysis World J Surg 1993;17:653-657.

12 Watanabe T, Yaegashi H, Koizumi M, et al. The lobular structure of the normal human pancreas: a computerassisted three dimensional reconstruction study. Pancreas 1997;15:48-52.

13 Akao S, Bockman DE, Lechene de La Porte P, et al. Three dimensional pattern of ductuloacinar associations in normal and pathological human pancreas. Gastroenterology 1983;85:55-66.

14 Klimstra DS. Pancreas. In: Sternberg SS (ed). Histology for Pathologist, 2nd edn. Lippincott-Raven publishers: Philadelphia, PA, 1997, pp 613-647.

15 Tompkins RK, Thomas D, Wile A, et al. Prognostic factors in bile duct carcinoma: analysis of 96 cases. Ann Surg 1981;194:447-455.

16 Yeo CJ, Sohn TA, Cameron JL, et al. Periampullary carcinoma: analysis of 5-year survivors. Ann Surg 1998;227:821-831.

17 Nagorney DM, Donohue JH, Farnell MB, et al. Outcomes after curative resections of cholangiocarcinoma. Arch Surg 1993;128:871-879.

18 Jarnagin WR, Koea JB, Klimstra DS. Cancers of the biliary tree: staging, technique, and pathology. In: Kelson DP, Daly JM, Kern SE, Levin B, Tepper JE (eds). Gastrointestinal Oncology. Lippincott Williams \& Wilkins: Philadelphia, PA, 2002, pp 615-643.

19 Kurosaki I, Tsukada K, Watanabe H, et al. Prognostic determinants in extrahepatic bile duct cancer. Hepatogastroenterology 1998;45:905-909.

20 Yeo CJ, Cameron JL, Sohn TA, et al. Six hundred fifty consecutive pancreaticoduodenectomies in the 1990s. Ann Surg 1997;226:248-260.

21 Kayahara M, Nagakawa T, Ohta T, et al. Role of nodal involvement and the periductal soft-tissue margin in middle and distal bile duct cancer. Ann Surg 1999;229:76-83.

22 Kelley ST, Bloomston M, Serafini F, et al. Cholangiocarcinoma: advocate an aggressive operative approach with adjuvant chemotherapy. Am Surg 2004;70: 743-748. 